\title{
PHALERIA MACROCARPA LEAF EXTRACT-CHITOSAN NANOPARTICLES SUPRESS ANGIOGENESIS INDUCED BY DEXTRAN SODIUM SULFATE IN MICE COLON
}

\author{
KUSMARDI KUSMARDI ${ }^{1}$, NUR AFIAHUDDIN TUMPU², ARI ESTUNINGTYAS ${ }^{3 *}$
}

1Department of Pathology Anatomy, Faculty of Medicine, Universitas Indonesia, Jakarta, Indonesia, ${ }^{2}$ Undergraduate Student of Faculty of Medicine, Universitas Indonesia, Jakarta, Indonesia, ${ }^{3}$ Department of Pharmacology, Faculty of Medicine, Universitas Indonesia, Jakarta, Indonesia

Email: ari.estuningtyas@ui.ac.id

Received: 14 Dec 2018, Revised and Accepted: 10 Mar 2019

\section{ABSTRACT}

Objective: Although an anti-inflammatory effect of Phaleria macrocarpa (Mahkota Dewa in Indonesian) leaf extract has been reported, the extract shows toxicity as the dose increases. Chitosan nanoparticles are known to have transport properties that can enhance the targeting of active compounds to tissues at a lower dose. The present study sought to determine whether the extract in chitosan nanoparticles can suppress angiogenesis in the colon tissue of mice.

Methods: We determined the antiangiogenic effect in 6 groups Swiss Webster mice: normal (N) group, negative control (NC) administered drinking water containing DSS $2 \% \mathrm{w} / \mathrm{v}(7 \mathrm{~d})$ and followed by water without DSS (7 d) in 3 cycles, 12.5 and 25 mg leaf extract of $P$. macrocarpa/mouse (EPM 12.5 and EPM 25) groups, and 6.25 and 12.5 mg leaf extract of P. macrocarpa in chitosan nanoparticles/mouse (NPPM 6.25 and NPPM 12.5) groups. Hematoxylin and eosin-stained samples was performed to determine the amount of angiogenesis in the colon tissue.

Results: The angiogenesis in the NPPM $12.5(\mathrm{p}=0.105)$ and EPM $25(\mathrm{p}=0.07)$ groups was not significantly different to that in the negative control group (administered DSS alone). By contrast, angiogenesis in the EPM 12.5 ( $p=0.03$ ) and NPPM 6.25 ( $p=0.02$ ) groups was significantly less than that in the DSS group.

Conclusion: Angiogenesis in the colon tissue of mice was reduced by the extract with or without chitosan nanoparticles. The greatest reduction was found for the $12.5 \mathrm{mg} / \mathrm{mouse}$ dose of P. macrocarpa leaf extract in chitosan nanoparticles.

Keywords: Angiogenesis, Anti-inflammation, Chitosan nanoparticles, Phaleria macrocarpa leaf extract

(C) 2019 The Authors. Published by Innovare Academic Sciences Pvt Ltd. This is an open access article under the CCBY license (http://creativecommons. org/licenses/by/4. 0/] DOI: http://dx.doi.org/10.22159/ijap.2019.v11s6.33574

\section{INTRODUCTION}

Inflammatory bowel disease (IBD) is a chronic inflammation of the digestive tract, which is induced by immunological reactions including Crohn's disease (CD) and ulcerative colitis (UC). Globally, there are 10 cases of IBD per 100,000 individuals, with a high incidence in Europe and North America. About 2.2-14.3 cases of UC per 100,000 individuals and 3.1-14.6 cases of CD per 100,000 individuals occur each year in North America [1]. In Indonesia, the incidence of UC is 0.55 cases per 100,000 individuals, while for CD the incidence is 0.33 cases per 100,000 individuals for period $2011-$ 2012. The incidence is increasing because of the unclear etiology and pathophysiology of the disease [2].

Persistent proinflammatory cytokine exposure in IBD leads to chronic inflammation. This condition is supported by one of the components that plays a role in angiogenesis as part of the inflammatory process. Angiogenesis is the natural process of new vascular formation to supply oxygen, nutrition, and several growth factors, thus maintaining the inflammation. Over time, chronic inflammation will initiate an oncogenic response such as mutation and epigenetic changes in the digestive tract, especially in the colon, and triggers progenitor cancer cell formation (cancer-associated colitis) [3, 4].

Anti-angiogenesis-based IBD treatment using several types of drugs has been developed. Anti-angiogenesis will inhibit the inflammation process by suppressing cytokine secretion and proangiogenic factor. Bevacizumab is one of most commonly used anti-angiogenic agents used with a high success rate. However, bevacizumab is known to cause serious side effects, such as intestinal perforation, impaired wound healing, and bleeding. Moreover, its high cost is a consideration for researchers attempting to discover alternative treatments that are not only safe but also affordable $[4,5]$.

The use of naturally occurring ingredients as anti-angiogenesis drugs has been studied extensively. Suprapti et al. [6] tested the effectiveness of Mahkota Dewa (Phaleria macrocarpa L.) leaf extract as an anti-inflammatory agent. Active compounds from the extract include kaempferol, quercetin, and phalerin, which have antiinflammatory and antiangiogenic effects, suggesting the extract as a potential candidate for IBD therapy. However, high doses of the extract were found to be toxic in animals [6]. Therefore, we sought to determine whether loading the extract in chitosan nanoparticles could facilitate better diffusion of the active compound to specific tissues to achieve antiangiogenic therapeutic effects with a lower extract dose than by using the extract alone [7].

\section{MATERIALS AND METHODS}

This experimental study in vivo used a randomized and parallel design and was conducted in the Pharmacokinetics Laboratory, Pharmacology and Therapeutic Department, Faculty of Medicine, Universitas Indonesia (FMUI) in 2018 with approval from the Health Research Ethics Committee of FMUI (approval no. 0747/UN2. F1/ETIK/2018).

\section{Animal sample preparation}

Male Swiss Webster mice aged $12 \mathrm{w}$ with an average body weight of about $25 \mathrm{~g}$ were obtained from the Animal Laboratory of the Center for Health Research and Development, Ministry of Health, Jakarta, and acclimatized for $7 \mathrm{~d}$ before treatment. The mice were housed in temperatures below $30{ }^{\circ} \mathrm{C}$ under a 12-h light/dark cycle, fed with standard feed, and allowed water ad libitum. Based on a power calculation, 36 mice were used and were divided into 6 groups that received different treatments: no treatment $(\mathrm{N})$, negative control (NC) administered drinking water containing DSS 2\% w/v (7 d) and followed by water without DSS (7 d) in 3 cycles, EPM 25 (DSS 2\% $\mathrm{w} / \mathrm{v}$ as described before $+25 \mathrm{mg} /$ mouse $P$. macrocarpa leaf extract for $5 \mathrm{w}$ orally, starting on week 2 (day 8), EPM 12.5 (DSS $2 \% \mathrm{w} / \mathrm{v}$ as described before $+12.5 \mathrm{mg}$ extract/mouse for $5 \mathrm{w}$ orally, starting on week 2 (day 8), NPPM 12.5 (DSS $2 \% \mathrm{w} / \mathrm{v}$ as described before+12.5 
mg extract in chitosan nanoparticles/mouse for $5 \mathrm{w}$ orally, starting on week 2 (day 8), NPPM 6.25: DSS $2 \% \mathrm{w} / \mathrm{v}$ as described before+6.25 mg extract in chitosan nanoparticles/mouse for $5 \mathrm{w}$ orally, starting on week 2 (day 8).

\section{Tissue preparation}

The mice were killed in week 7 by cervical dislocation. Then, colon tissues were harvested and cleaned with water. Colon tissues were fixed for $24-48 \mathrm{~h}$ with a $10 \%$ formalin buffer, dehydrated, cleared through a graduated series of increasing concentrations of xylol solutions, and infiltrated with paraffin using an automatic tissue processor. Subsequently, the colon tissues were embedded into paraffin medium in a box cassette and sliced at a thickness of 3-5 $\mu \mathrm{m}$ using a microtome. The slices were placed in a water bath (40$50{ }^{\circ} \mathrm{C}$ ), fixed to glass slides, and dried for $1 \mathrm{~h}$ at $40^{\circ} \mathrm{C}$.

\section{Hematoxylin and eosin staining}

The colon tissue sections fixed on the slides were saturated with xylol I and xylol II for 5 min each and then submerged in a graduated series of ethanol solutions $(90 \%, 75 \%$, and $70 \%)$ for 5 min each. Then, the sections were stained by soaking them in a hematoxylin solution for 5-10 min, followed by rinsing them under water. Subsequently, the sections were dipped into a lithium carbonate solution, followed by another water rinse. Then, the sections were soaked in an eosin solution for 1-3 min, followed by 3 times dehydrating them through a graduated series of alcohol concentrations $(70 \%, 75 \%$, and $90 \%)$. After that, the sections were dipped into xylol I and xylol II solutions for about 5 min each.
Finally, each section was covered with 1 drop of Ingelan and a cover glass.

\section{Interpretation of hematoxylin and eosin staining}

The histology of colon tissue samples was performed using a Leica light microscope and Sigma camera at $400 \times$ magnification. Examination was conducted in 10 fields of view for each sample. The amount of angiogenesis appearance was calculated manually by the Image-J program. After that, received data was interpreted to obtain a valid data conclusion.

\section{Data analysis}

The distributions of data were analyzed using a Shapiro-Wilk test, followed by a one-way ANOVA with a Tukey post hoc test to compare more than 2 groups. Nonhomogeneously distributed data were analyzed using a nonparametric Kruskal-Wallis test followed by a Mann-Whitney U test.

\section{RESULTS}

All of the doses of leaf extracts were found to reduce inflammation in mouse colon tissue induced by DSS (fig. 1). The amount of angiogenesis was significantly less in the EPM $12.5(\mathrm{p}=0.03)$ and NPPM $6.25(p=0.02)$ groups compared with that in the NC group. By contrast, the EPM $25(p=0.07)$ and NPPM $12.5(p=0.105)$ groups showed no significant difference in angiogenesis compared with that in the NC group. No significant differences were found between the treatment groups. The histopathological features of angiogenesis appearance was presented in fig. 2.

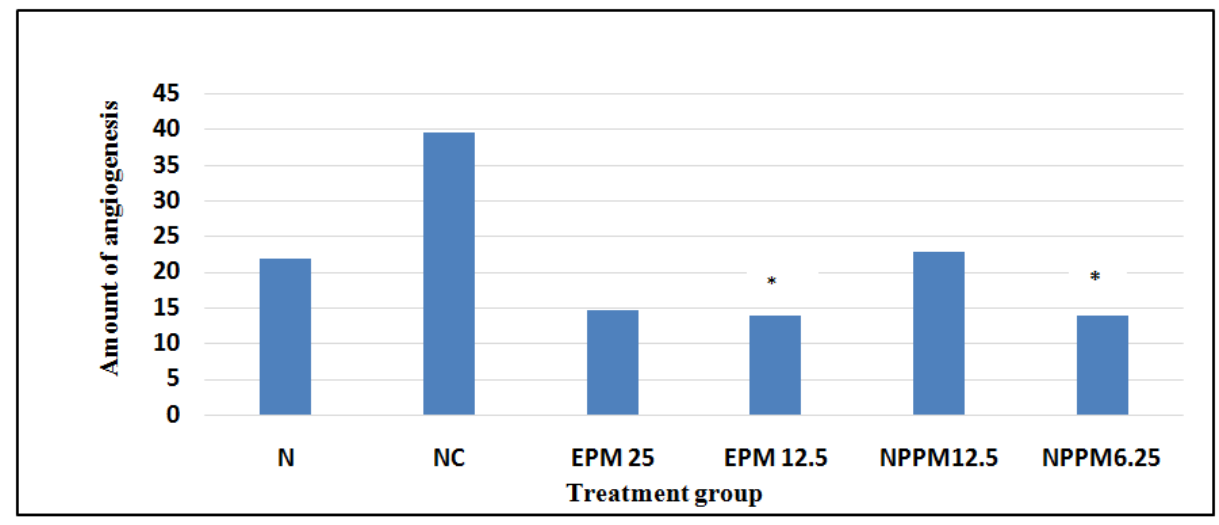

Fig. 1: Mean amount of angiogenesis on mice colon, Note: $\mathrm{N}=$ no treatment group; $\mathrm{NC}=$ negative control group; $\mathrm{EPM} 25=$ Phaleria macrocarpa leaf extract dose $25 \mathrm{mg} / \mathrm{mouse}$; EPM $12.5=12.5 \mathrm{mg}$ extract/mouse; NPPM $12.5=12.5 \mathrm{mg}$ extract in chitosan nanoparticles/mouse; NPPM $6.25=6.25 \mathrm{mg}$ extract in chitosan nanoparticles; ${ }^{*}=$ significant difference to $\mathrm{NC}$ group

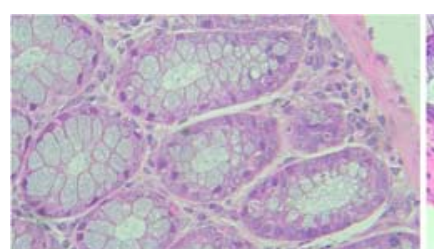

N Group

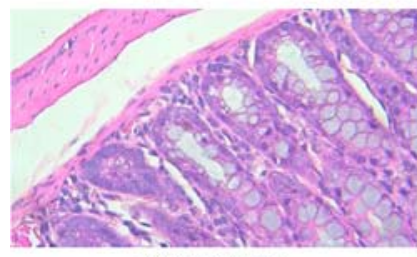

EPM12.5 Group

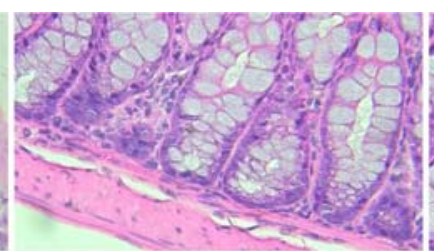

NC Group

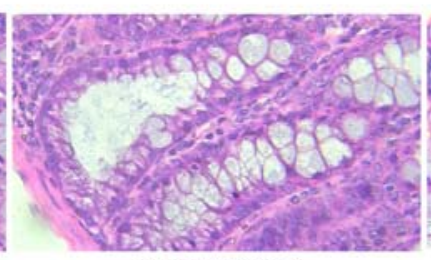

NPPM12.5 Group

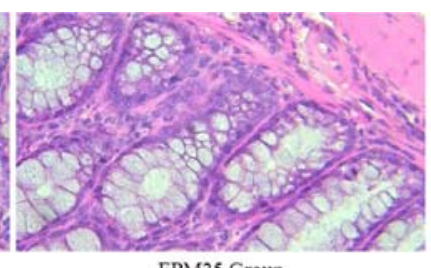

EPM25 Group

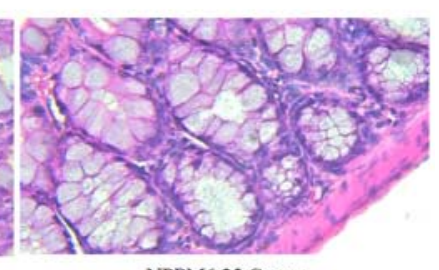

NPPM6.25 Group

Fig. 2: Mice colon tissue after hematoxylin and eosin staining (400 $\times$ magnification), Note: $\mathbf{N}=$ no treatment group; $\mathrm{NC}=$ negative control group; EPM 25 = Phaleria macrocarpa leaf extract dose $25 \mathrm{mg} / \mathrm{mouse}$; EPM 12.5 = $12.5 \mathrm{mg}$ extract/mouse; NPPM 12.5 = 12.5 mg extract in chitosan nanoparticles/mouse; NPPM $6.25=6.25 \mathrm{mg}$ extract in chitosan nanoparticles; ${ }^{*}=$ significant difference to NC group 


\section{DISCUSSION}

P. macrocarpa leaf extract contains several flavonoid subtypes, such as quercetin, phalerin, and kaempferol which have antiinflammatory, especially anti-angiogenesis properties. We used DSS, a polyamine dextran, to induce impairment of gastrointestinal permeability and colonic mucosal barrier function. This condition triggers cell dysfunction and immune system reactions. We used the extracts to reduce cell damage and immune responses. The extract is toxic at high dosage. Because of the toxicity, we used chitosan nanoparticles to carry the leaf extract to increase targeted drug delivery so that the efficacy of extract action could be enhanced.

Histopathology features showed the ability of the extract to suppress the amount of angiogenesis induced by DSS in mice colon tissues, possibly due to the anti-inflammatory effects of flavonoids, such as kaempferol, which can reduce inflammatory reaction by inhibiting of NF- $\kappa B$ activity [6]. The description of the inhibition of angiogenesis by $P$. macrocarpa leaf extract can be caused by the effect of $P$. macrocarpa on anti-inflammatory. The effect of $P$. macrocarpa on inflammation is shown by previous studies. This study showed an inhibition of the expression of iNOS protein in the cryptic colon epithelial cells induced by DSS $[8,9]$. The incidence of inhibitory effects is also in line with the increase in the extract dose of $P$. macrocarpa. This inhibition can prevent the aggregation of proinflammatory cells and cytokines. The amount of angiogenesis was found significantly reduced in all of the treatment groups, especially the EPM 12.5 and NPPM 6.25 groups.

\section{CONCLUSION}

Administration of P. macrocarpa leaf extract directly or carried by chitosan nanoparticles has the same ability to reduce the amount of angiogenesis in the inflammation reaction induced by DSS in mouse colon. EPM 12.5 and NPPM 6.25 groups showed significant reduction compared with that in the NC group.

\section{ACKNOWLEDGEMENT}

The authors wish to thank to The Directorate of Research and Community of Service of Universitas Indonesia for a PITTA grant. This article was presented at The 3rd International Conference and Exhibition on Indonesian Medical Education and Research Institute (ICE on IMERI 2018), Faculty of Medicine, Universitas Indonesia, Jakarta, Indonesia. We thank the 3rd ICE on IMERI Committee who had supported the peer review and manuscript preparation before submitting to the journal.

\section{AUTHORS CONTRIBUTIONS}

All the author have contributed equally

\section{CONFLICT OF INTERESTS}

There are no conflicts of interest to declare

\section{REFERENCES}

1. Friedman S, Blumberg RS. Inflammatory bowel disease. In: Longo DL, Fauci AS. editors. Harrison's gastroenterology and hepatology. $2^{\text {nd }}$ ed. New York: McGraw Hill Education; 2013. p. 179-85.

2. Ng WK, Wong SH, Ng SC. Changing epidemiological trends of inflammatory bowel disease in Asia. Int Res 2016;14:111-9.

3. Grivennikov SI. Inflammation and colorectal cancer: colitisassociated neoplasia. Semin Immunopathol 2013;35:229-44.

4. Alkim C, Alkim H, Koksal AR, Boga S, Sen I. Angiogenesis in inflammatory bowel disease. Int J Inflammation 2015;970890.

5. Pavlidis ET, Pavlidis TE. Role of bevacizumab in colorectal cancer growth and its adverse effect: a review. World J Gastroenterol 2013;19:5051-60.

6. Suprapti T, Louisa M, Tedjo A, Kusmardi Fadilah, Handjari DR, Yulhasri. Antiinflammatory effect of phaleria macrocarpa (Phaleria macrocarpa (Scheff.) Boerl.) leaves extract on colon carcinogenesis induced by azoxymethane and dextran sodium sulphate: focus on the iNOS, $\beta$-catenin, and COX-2 expressions. Asian J Appl Sci 2014;2:511-27.

7. Wang JJ, Zeng ZW, Xiao RZ, Xie T, Zhou GL, Zhan XR, et al. Recent advances of chitosan nanoparticles as drug carriers. Int J Nanomed 2011;6:765-74.

8. Kusmardi K, Estuningtyas A, Shavera D, Tedjo A, Priyosoeryanto BP. The effect of mahkota dewa (Phaleria Macrocarpa) (Scheff.) fruit pericarp extract on iNOs in mice colon intermittenly induced by dextran sodium sulfate. Asian J Pharm Clin Res 2017;10:309-12.

9. Estuningtyas A, Widiasari S, Louisa M, Kusmardi K. The effect of mahkota dewa (Phaleria macrocarpa L) leaf extract encapsulated in chitosan nanoparticles on iNOS and COX-2 expression in dextran sodium sulphate-induced colitis mice model. JIDMR 2019;1:220-6. 